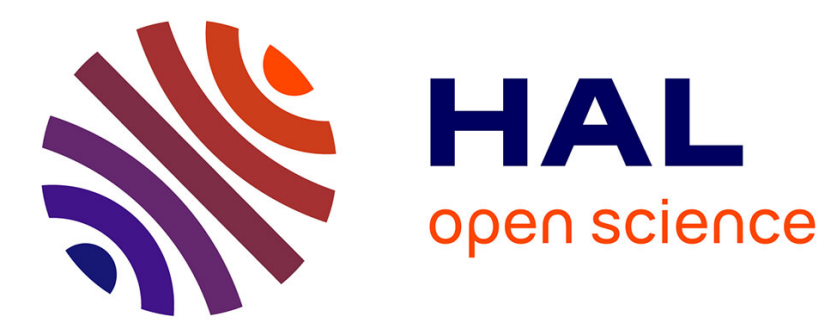

\title{
The BF-TOPSIS Approach for Solving Non-classical MCDM Problems
}

Jean Dezert, Deqiang Han, Jean-Marc Tacnet, Simon Carladous, Yin Hanlin

\section{To cite this version:}

Jean Dezert, Deqiang Han, Jean-Marc Tacnet, Simon Carladous, Yin Hanlin. The BF-TOPSIS Approach for Solving Non-classical MCDM Problems. 4th International Conference, BELIEF 2016, Sep 2016, Prague, Czech Republic. pp.75-83, 10.1007/978-3-319-45559-4_8 . emse-01364911

\section{HAL Id: emse-01364911 \\ https://hal-emse.ccsd.cnrs.fr/emse-01364911}

Submitted on 14 Jun 2021

HAL is a multi-disciplinary open access archive for the deposit and dissemination of scientific research documents, whether they are published or not. The documents may come from teaching and research institutions in France or abroad, or from public or private research centers.
L'archive ouverte pluridisciplinaire $\mathbf{H A L}$, est destinée au dépôt et à la diffusion de documents scientifiques de niveau recherche, publiés ou non, émanant des établissements d'enseignement et de recherche français ou étrangers, des laboratoires publics ou privés. 


\title{
The BF-TOPSIS Approach for Solving Non-classical MCDM Problems
}

\author{
Jean Dezert ${ }^{1(\bowtie)}$, Deqiang Han $^{2}$, Jean-Marc Tacnet ${ }^{3}$, Simon Carladous ${ }^{3,4,5}$, \\ and Hanlin Yin ${ }^{2}$ \\ 1 The French Aerospace Lab, 91761 Palaiseau, France \\ jean.dezert@onera.fr \\ 2 CIESR, Xi'an Jiaotong University, Xi'an 710049, China \\ deqhan@gmail.com, iverlon1987@stu.xjtu.edu.cn \\ 3 UGA, Irstea, UR ETGR, \\ 2 rue de la Papeterie-BP 76, 38402 St-Martin-d'Hères, France \\ \{jean-marc.tacnet, simon. carladous\}@irstea.fr \\ 4 AgroParisTech, 19 avenue du Maine, 75732 Paris, France \\ 5 ENSMSE - DEMO, 29, rue Ponchardier, 42100 Saint-Etienne, France
}

\begin{abstract}
In this paper we show how the Belief-Function based Technique for Order Preference by Similarity to Ideal Solution (BF-TOPSIS) approach can be used for solving non-classical multi-criteria decisionmaking (MCDM) problems. We give simple examples to illustrate our presentation.
\end{abstract}

Keywords: Multi-criteria decision-making $\cdot$ Belief functions $\cdot$ TOPSIS · BF-TOPSIS

\section{Introduction}

Classical Multi-Criteria Decision-Making (MCDM) consists in choosing an alternative among a known set of alternatives based on their quantitative evaluations (numerical scores) obtained with respect to different criteria. A typical example could be the selection of a car to buy among a given set of cars based on different criteria (cost, engine robustness, fuel economy, $\mathrm{CO}_{2}$ emission, etc.). The classical MCDM problem, although easily formulated, have no solution at all in general due to the fact that no alternative exists that optimizes all criteria jointly. Thus MCDM problems are generally not solved, but a decision is found by means of ranking, compromises etc. The difficulty of MCDM problems is also because the scores are usually expressed in different (physical) units with different scales which generally necessitates an ad-hoc choice of a normalization step that may lead to many problems, e.g. rank reversal.

Many methods have been developed to address the classical MCDM. AHP ${ }^{1}$ [1] and its extensions in belief function frameworks [2-6], ELECTRE ${ }^{2}$ [7],

\footnotetext{
${ }^{1}$ Analytic hierarchy process.

${ }^{2}$ Elimination and choice translating reality.
} 
TOPSIS $^{3}[8,9]$ methods are the most well-known and widely used MCDM methods in applications. These methods have already been extended in the belief function framework in our previous works $[2,10,11]$ to take into account epistemic uncertainty, missing scores' values as well as conflicting information between sources $^{4}$. In this work, we show how the BF-TOPSIS methods proposed recently in [11] (with application in [12]), can be directly used for solving also nonclassical multicriteria decision-making problems where not only alternatives are scored (with possibly missing values), but also any element of the power set of alternatives.

In the sequel, we assume the reader to be familiar with the theory of belief functions [13] and its definitions and notations, mainly the basic belief assignment (BBA) $m(\cdot)$, the belief function $\operatorname{Bel}(\cdot)$ and the plausibility function $P l(\cdot)$ defined with respect to a discrete finite frame of discernment (FoD).

\section{Non-classical MCDM Problem Formulation}

We consider a given set of alternatives $\mathcal{A} \triangleq\left\{A_{1}, A_{2}, \ldots, A_{M}\right\}(M>2)$ representing the FoD of our problem under consideration, and we denote $2^{\mathcal{A}}$ the power $\operatorname{set}^{5}$ of $\mathcal{A}$. In our approach, we work with Shafer's classical model of FoD and we do not allow the empty set to be a focal element ${ }^{6}$ because in our opinion it does not make sense to compare an alternative with respect to the empty set from the decision-making standpoint. The cardinality of the (non empty) elements of the power set varies from 1 to $2^{M}-1$. We also consider a given set of criteria $\mathcal{C} \triangleq\left\{C_{1}, C_{2}, \ldots, C_{N}\right\}(N \geq 1)$, where each criterion $C_{j}$ is characterized by a relative importance weighting factor $w_{j} \in[0,1], j=1, \ldots, N$ such that $\sum_{j=1}^{N} w_{j}=1$. The set of normalized weighting factors is denoted by $\mathbf{w}=\left\{w_{1}, w_{2}, \ldots, w_{N}\right\}$. The score ${ }^{7}$ value is a number $S_{i j}=S_{j}\left(X_{i}\right)$ related to the evaluation of an element $X_{i} \in 2^{\mathcal{A}} \backslash\{\emptyset\}$ from a given criterion $C_{j}$. If the score value $S_{j}\left(X_{i}\right)$ is not available (or missing), we denote it by the "varnothing" symbol $\varnothing$. The non-classical MCDM problem can be formulated as follows in the worst case (i.e. when scores apply to all elements of $2^{\mathcal{A}}$ ): given the $\left(2^{M}-1\right) \times N$ score matrix $\mathbf{S}=\left[S_{j}\left(X_{i}\right)\right]$ whose elements take either a numerical value or a $\varnothing$ value (if the value is not available) and knowing the set $\mathbf{w}$ of the relative importance weights of criteria, how to rank the elements of $2^{\mathcal{A}} \backslash\{\emptyset\}$ to make the final decision?

\footnotetext{
3 Technique for order preference by similarity to ideal solution.

${ }^{4}$ In the MCDM context, a source of information consists in the list of scores values of alternatives related to a given criterion.

${ }^{5}$ The power set $2^{\mathcal{A}}$ is the set of all subsets of $\mathcal{A}$, empty set $\emptyset$ and $\mathcal{A}$ included.

${ }^{6}$ As proposed in Smets Transferable Belief Model for instance.

${ }^{7}$ Depending on the context of the MCDM problem, the score can be interpreted either as a cost/expense or as a reward/benefit. In the sequel, by convention and without loss of generality, we will interpret the score as a reward having monotonically increasing preference. Thus, the best alternative with respect to a given criterion will be the one providing the highest reward/benefit.
} 
Example: Let us consider the ranking of five students $A_{1}, \ldots, A_{5}$ based on two criteria $C_{1}$ and $C_{2}$. The criterion $C_{1}$ is their long jump performance (in meters), and the criteria $C_{2}$ is a realization of a small project to collect funds (in euros) to help a bigger nature protection project. Highest scores values mean better results in this particular context. Let us assume that students were allowed to realize their project in joint collaboration (no more than three students are allowed in a group), or alone. At the end term of the project, suppose that one has the two following evaluations (scoring)

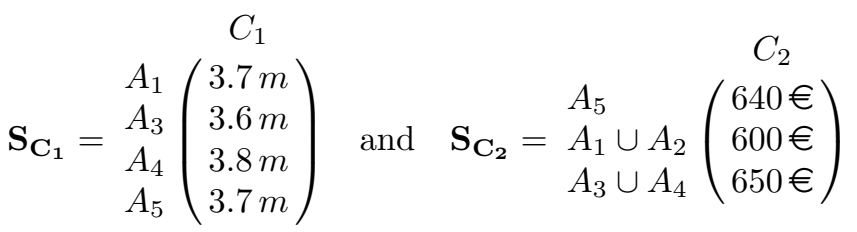

The scores' values listed in $\mathbf{S}_{\mathbf{C}_{\mathbf{1}}}$ indicate in fact that the student $A_{2}$ has not been able to pass the long jump test for some reason (medical, familial or whatever), so his score is missing. The scores' values listed in $\mathbf{S}_{\mathbf{C}_{\mathbf{2}}}$ indicate that $A_{5}$ did choose to realize his project alone with a pretty good performance, and the project realized by the collaboration of students $A_{3}$ with $A_{4}$ has obtained the best performance (the highest amount of collected funds). In this very simple example, one sees that the score evaluation can be done not only on single alternatives (as for criterion $C_{1}$ ) but also on a subset of elements of $2^{\mathcal{A}}$ (as for criterion $C_{2}$ ). All the elements having a score are called scoring focal elements. In general, these focal elements can differ from one criterion $C_{j}$ to another criterion $C_{k}$ for $k \neq j$ and the score matrix cannot be built by a simple (horizontal) stacking of scoring lists. In general, one must identify all focal elements of each scoring list to determine the minimum number of rows necessary to define the scoring matrix. As mentioned, we use the symbol $\varnothing$ to identify all values that are missing in the scoring matrix. Note that we do not set missing values to zero number (or any other chosen number) to make explicit distinction between the known precise numerical value zero and a missing value. In this example, the scoring matrix will be defined as

$$
\left.\mathbf{S}=\begin{array}{ccc} 
& C_{1} & C_{2} \\
A_{1} & 3.7 m & \varnothing \\
A_{3} & 3.6 m & \varnothing \\
A_{4} & 3.8 m & \varnothing \\
A_{5} & 3.7 m & 640 € \\
A_{1} \cup A_{2} & \varnothing & 600 € \\
A_{3} \cup A_{4} & \varnothing & 650 €
\end{array}\right)
$$

The question we want to address is how to rank the students based on such a kind of scoring information including disjunctions of alternatives and missing values, taking into account the relative importance weight of each criterion. Is it possible to solve such type of non-classical MCDM problems, and how? 


\section{The BF-TOPSIS Approach}

The BF-TOPSIS approach has been proposed recently in [11] in a classical MCDM context where the focal elements of the scoring function $S_{j}(\cdot)$ $(j=1, \ldots, N)$ are only the singletons $A_{i}(i=1, \ldots, M)$ of the frame of discernment $\mathcal{A}$. BF-TOPSIS is initially based on belief functions for MCDM support which exploits only the $M \times N$ score matrix $\mathbf{S}=\left[S_{j}\left(A_{i}\right)\right]$ and the relative importance weighting factors of criteria. The first main step of BF-TOPSIS is the construction of an $M \times N$ BBA matrix $\mathbf{M}=\left[m_{i j}(\cdot)\right]$ from the score matrix $\mathbf{S}$, and then the combination of components of $\mathbf{M}$ to make a final decision thanks to the Euclidean belief interval distance, denoted by $d_{B I}$, defined in $[14,15]$.

In fact, the BF-TOPSIS approach can also be directly applied to solve the non-classical MCDM problems because the belief interval $\left[\operatorname{Bel}_{i j}\left(X_{i}\right), P l_{i j}\left(X_{i}\right)\right]$ of each proposition (i.e. each focal element which is not necessarily a singleton) $X_{i}$ based on a criteria $C_{j}$ can be established in a consistent manner ${ }^{8}$ from the score matrix $\mathbf{S}=\left[S_{j}\left(X_{i}\right)\right]$ as follows

$$
\left[\operatorname{Bel}_{i j}\left(X_{i}\right) ; P l_{i j}\left(X_{i}\right)\right] \triangleq\left[\frac{\operatorname{Sup}_{j}\left(X_{i}\right)}{X_{\max }^{j}} ; 1-\frac{\operatorname{Inf} f_{j}\left(X_{i}\right)}{X_{\min }^{j}}\right]
$$

where the $\operatorname{Sup}_{j}\left(X_{i}\right)$ and $\operatorname{Inf}_{j}\left(X_{i}\right)$ are computed from the score matrix $\mathbf{S}$ by

$$
\begin{gathered}
\operatorname{Sup}_{j}\left(X_{i}\right) \triangleq \sum_{Y \in 2^{\mathcal{A}} \mid S_{j}(Y) \leq S_{j}\left(X_{i}\right)}\left|S_{j}\left(X_{i}\right)-S_{j}(Y)\right| \\
\operatorname{Inf}_{j}\left(X_{i}\right) \triangleq-\sum_{Y \in 2^{\mathcal{A}} \mid S_{j}(Y) \geq S_{j}\left(X_{i}\right)}\left|S_{j}\left(X_{i}\right)-S_{j}(Y)\right|
\end{gathered}
$$

$\operatorname{Sup}_{j}\left(X_{i}\right)$ is called the "positive support" of $X_{i}$ because it measures how much $X_{i}$ is better than other propositions according to criterion $C_{j}$, and $\operatorname{In} f_{j}\left(X_{i}\right)$ is called the "negative support" of $X_{i}$ because it measures how much $X_{i}$ is worse than other propositions according to criterion $C_{j}$. The length of interval $\left[0, \operatorname{Sup}_{j}\left(X_{i}\right)\right]$ measures the support in favor of $X_{i}$ as being the best proposition with respect to all other ones, and the length of $\left[\operatorname{In} f_{j}\left(X_{i}\right), 0\right]$ measures the support against $X_{i}$ based on the criterion $C_{j}$.

The denominators involved in (3), are defined by $X_{\max }^{j} \triangleq \max _{i} \operatorname{Sup}_{j}\left(X_{i}\right)$ and $X_{\text {min }}^{j} \triangleq \min _{i} \operatorname{Inf}_{j}\left(X_{i}\right)$, and they are supposed different from zero ${ }^{9}$. From the belief interval $\left[\operatorname{Bel}_{i j}\left(X_{i}\right) ; P l_{i j}\left(X_{i}\right)\right]$, we obtain the BBA $m_{i j}(\cdot)$ defined by

$$
\begin{aligned}
m_{i j}\left(X_{i}\right) & \triangleq \operatorname{Bel}_{i j}\left(X_{i}\right) \\
m_{i j}\left(\bar{X}_{i}\right) & \triangleq \operatorname{Bel}_{i j}\left(\bar{X}_{i}\right)=1-P l_{i j}\left(X_{i}\right) \\
m_{i j}\left(X_{i} \cup \bar{X}_{i}\right) & \triangleq P l_{i j}\left(X_{i}\right)-\operatorname{Bel}_{i j}\left(X_{i}\right)
\end{aligned}
$$

${ }^{8}$ Indeed, $\operatorname{Bel}_{i j}\left(X_{i}\right)$ and $\operatorname{Bel}_{i j}\left(\bar{X}_{i}\right)$ (where $\bar{X}_{i}$ is the complement of $X_{i}$ in the FoD $\mathcal{A}$ ) belong to $[0,1]$ and they are consistent because the equality $P l_{i j}\left(X_{i}\right)=1-\operatorname{Bel}_{i j}\left(\bar{X}_{i}\right)$ holds. The proof is similar to the one given in [11].

${ }^{9}$ If $X_{\text {max }}^{j}=0$ then $B e l_{i j}\left(X_{i}\right)=0$, and if $X_{\text {min }}^{j}=0$ then $P l_{i j}\left(X_{i}\right)=1$, so that $\operatorname{Bel}_{i j}\left(\bar{X}_{i}\right)=0$. 
If a numerical value $S_{j}\left(X_{i}\right)$ is missing in the score matrix $\mathbf{S}$ (it is equal to $\varnothing$ ), one chooses $m_{i j}(\cdot)$ equals $(0,0,1)$, i.e., one takes a vacuous belief assignment. In [11], we have proposed four methods (called BF-TOPSIS1, ..., BFTOPSIS4) to make a decision from the BBA matrix $\mathbf{M}=\left[m_{i j}(\cdot)\right]$. Due to space restriction constraint, we just recall the principle of the BF-TOPSIS1 method because it is the simplest one. Applications of BFTOPSIS2-BFTOPSIS4 methods to non-classical MCDM problems is also possible without difficulty. The proposed transformation of score values to BBAs and basis of BF-TOPSIS method are theoretically justified in [11].

Before presenting succinctly the BF-TOPSIS1 method, we need to recall the definition of Belief Interval-based Euclidean distances $d_{B I}\left(m_{1}, m_{2}\right)$ introduced in [14] between two BBAs $m_{1}(\cdot)$ and $m_{2}(\cdot)$ defined on a same FoD $\Theta$. Mathematically, $d_{B I}\left(m_{1}, m_{2}\right)$ is defined by

$$
d_{B I}\left(m_{1}, m_{2}\right) \triangleq \sqrt{N_{c} \cdot \sum_{X \in 2^{\Theta}} d_{W}^{2}\left(B I_{1}(X), B I_{2}(X)\right)}
$$

where $N_{c}=1 / 2^{|\Theta|-1}$ is a normalization factor to have $d_{B I}\left(m_{1}, m_{2}\right) \in[0,1]$, and $d_{W}\left(B I_{1}(X), B I_{2}(X)\right)$ is the Wassertein distance [16] between belief intervals $B I_{1}(X) \triangleq\left[B e l_{1}(X), P l_{1}(X)\right]=\left[a_{1}, b_{1}\right]$ and $B I_{2}(X) \triangleq\left[B e l_{2}(X), P l_{2}(X)\right]=$ $\left[a_{2}, b_{2}\right]$. More specifically,

$$
d_{W}\left(\left[a_{1}, b_{1}\right],\left[a_{2}, b_{2}\right]\right) \triangleq \sqrt{\left[\frac{a_{1}+b_{1}}{2}-\frac{a_{2}+b_{2}}{2}\right]^{2}+\frac{1}{3}\left[\frac{b_{1}-a_{1}}{2}-\frac{b_{2}-a_{2}}{2}\right]^{2}}
$$

In [14], we have proved that $d_{B I}(x, y)$ is a true distance metric.

Principle of BF-TOPSIS1: From the BBA matrix $\mathbf{M}$ and for each proposition (focal element) $X_{i}$, one computes the Belief Interval-based Euclidean distances $d_{B I}\left(m_{i j}, m_{i j}^{\text {best }}\right)$ defined in (9) between the BBA $m_{i j}(\cdot)$ and the ideal best BBA defined by $m_{i j}^{\text {best }}\left(X_{i}\right)=1$, and the distance $d_{B I}\left(m_{i j}, m_{i j}^{\text {worst }}\right)$ between $m_{i j}(\cdot)$ and the ideal worst BBA defined by $m_{i j}^{\text {worst }}\left(\bar{X}_{i}\right)=1$.

Then, one computes the weighted average of $d_{B I}\left(m_{i j}, m_{i j}^{\text {best }}\right)$ values with relative importance weighting factor $w_{j}$ of criteria $C_{j}$. Similarly, one computes the weighted average of $d_{B I}\left(m_{i j}, m_{i j}^{\text {worst }}\right)$ values. More specifically, one computes

$$
\begin{aligned}
d^{\text {best }}\left(X_{i}\right) & \triangleq \sum_{j=1}^{N} w_{j} \cdot d_{B I}\left(m_{i j}, m_{i j}^{\text {best }}\right) \\
d^{\text {worst }}\left(X_{i}\right) & \triangleq \sum_{j=1}^{N} w_{j} \cdot d_{B I}\left(m_{i j}, m_{i j}^{\text {worst }}\right)
\end{aligned}
$$

The relative closeness of the proposition $X_{i}$ with respect to ideal best solution $X^{\text {best }}$ defined by

$$
C\left(X_{i}, X^{\text {best }}\right) \triangleq \frac{d^{\text {worst }}\left(X_{i}\right)}{d^{\text {worst }}\left(X_{i}\right)+d^{\text {best }}\left(X_{i}\right)}
$$


is used to make the preference ordering according to the descending order of $C\left(X_{i}, X^{\text {best }}\right) \in[0,1]$, where a larger $C\left(X_{i}, X^{\text {best }}\right)$ value means a better proposition $X_{i}$.

Note that once the BBA matrix is computed from Eqs. (6), (7) and (8), we can also apply (if we prefer) BF-TOPSIS2, BF-TOPSIS3 or BFTOPSIS4 methods to make the final decision. Their presentation is out of the scope of this paper.

\section{Apply BF-TOPSIS to Non-classical MCDM Problems}

Due to space limitation restriction, we present the results of the BF-TOPSIS1 method only for two simple non-classical MCDM problems.

Example 1: This example is given by the score matrix of Eq. (2). We consider the relative importance weights $w_{1}=1 / 3$ and $w_{2}=2 / 3$ of criteria $C_{1}$ and $C_{2}$ respectively. Applying BBA construction formulas (6), (7) and (8) for this example $^{10}$, we get the BBA matrix $\mathbf{M}=\left[\left(m_{i j}\left(X_{i}\right), m_{i j}\left(\bar{X}_{i}\right), m_{i j}\left(X_{i} \cup \bar{X}_{i}\right)\right)\right]$ with

$$
\begin{aligned}
& C_{1} \quad C_{2} \\
& \mathbf{M}=\begin{array}{c}
A_{1} \\
A_{3} \\
A_{4} \\
A_{5} \\
A_{1} \cup A_{2} \\
A_{3} \cup A_{4}
\end{array}\left(\begin{array}{ccc}
(0.25,0.25,0.50) & (0,0,1) \\
(0,1,0) & (0,0,1) \\
(1,0,0) & (0,0,1) \\
(0,0,1) & (0,1,0) \\
(0,0,1) & (1,0,0)
\end{array}\right)
\end{aligned}
$$

From this matrix $\mathbf{M}$, we compute the distances $d_{B I}(.,$.$) with respect to ideal$ best and worst solutions shown in Table 1 . Table 2 provides $d^{\text {best }}\left(X_{i}\right), d^{\text {worst }}\left(X_{i}\right)$ and $C\left(X_{i}, X^{\text {best }}\right)$ values computed from the formulas (11), (12) and (13). Based on $C\left(X_{i}, X^{\text {best }}\right)$ values sorted in descending order, we finally get the preference order $\left(A_{3} \cup A_{4}\right) \succ A_{5} \succ A_{4} \succ A_{1} \succ\left(A_{1} \cup A_{2}\right) \succ A_{3}$. If we restrict the preference order to only singletons, we will get $A_{5} \succ A_{4} \succ A_{1} \succ A_{3}$ (i.e. student $A_{5}$ is the best one). Note that student $A_{2}$ alone cannot be ranked with respect to the other students, which is normal based on the non-specific input (scoring) information one has for him. Of course ad-hoc ranking solutions to rank all five students can always be developed ${ }^{11}$, but without necessarily preserving the compatibility with the rank obtained previously.

Example 2: In mountains, protecting housing areas against torrential floods is based on a lot of alternatives at the watershed scale such as check dams' series, sediment traps, dikes, and individual protections [12]. Moreover, alternatives can be the maintenance of existing structures or the construction of new ones to

${ }^{10}$ When a score value is missing for some proposition $X_{i}$ (i.e. if $S_{j}\left(X_{i}\right)=\varnothing$ ), then we take the vacuous BBA $m_{i j}\left(X_{i} \cup \bar{X}_{i}\right)=1$.

${ }^{11}$ For instance by normalizing the $C\left(X_{i}, X^{\text {best }}\right)$ values (the most right column of Table 2) and interpret it as a BBA, and then apply a decision method described in $[15]$. 
Table 1. Distances to ideal best and worst solutions.

\begin{tabular}{l|l|l|l|l}
\hline Focal elem. $X_{i}$ & $d_{B I}\left(m_{i 1}, m^{\text {best }}\right)$ & $d_{B I}\left(m_{i 1}, m^{\text {worst }}\right)$ & $d_{B I}\left(m_{i 2}, m^{\text {best }}\right)$ & $d_{B I}\left(m_{i 2}, m^{\text {worst }}\right)$ \\
\hline$A_{1}$ & 0.6016 & 0.2652 & 0.7906 & 0.2041 \\
\hline$A_{3}$ & 0.8416 & 0 & 0.7906 & 0.2041 \\
\hline$A_{4}$ & 0 & 0.8416 & 0.7906 & 0.2041 \\
\hline$A_{5}$ & 0.6016 & 0.2652 & 0.2674 & 0.5791 \\
\hline$A_{1} \cup A_{2}$ & 0.5401 & 0.3536 & 0.6770 & 0 \\
\hline$A_{3} \cup A_{4}$ & 0.5401 & 0.3536 & 0 & 0.6770 \\
\hline
\end{tabular}

Table 2. Average distances and relative closeness indicators.

\begin{tabular}{l|l|l|l|l}
\hline Focal elem. $X_{i}$ & $d^{\text {best }}\left(X_{i}\right)$ & $d^{\text {worst }}\left(X_{i}\right)$ & $C\left(X_{i}, X^{\text {best }}\right)$ & Ranking \\
\hline$A_{1}$ & 0.7276 & 0.2245 & 0.2358 & 4 \\
\hline$A_{3}$ & 0.8076 & 0.1361 & 0.1442 & 6 \\
\hline$A_{4}$ & 0.5270 & 0.4166 & 0.4415 & 3 \\
\hline$A_{5}$ & 0.3788 & 0.4745 & 0.5561 & 2 \\
\hline$A_{1} \cup A_{2}$ & 0.6314 & 0.1179 & 0.1573 & 5 \\
\hline$A_{3} \cup A_{4}$ & 0.1800 & 0.5692 & 0.7597 & 1 \\
\hline
\end{tabular}

increase the protection level. Final propositions generally involve several of previous individual alternatives. We propose here a simplified case of application. Within a given watershed, a check-dams' series already exists. Older than one century years old, its maintenance (alternative $A_{1}$ ) is questioned. Some experts propose to abandon it and to build a sediment trap upstream the alluvial fan (alternative $A_{2}$ ) or to limit damage on buildings through individual protections (alternative $A_{3}$ ). The Decision-Maker (DM), here the local municipality, must decide the best proposition taking into account several criteria: the investment cost $\left(C_{1}\right.$ in $€$, in negative values), the risk reduction in 50 years between the current situation and the expected situation after each proposition implementation $\left(C_{2}\right.$ in $\left.€\right)$, the impact on environment $\left(C_{3}\right.$ is a grade from 1 to 10$)$, and the land-use areas needed in privates $\left(C_{4}\right.$ in $\mathrm{m}^{2}$, in negative values). For each criterion, the higher is the score, the better is the proposition. The DM gives the same importance weight to $C_{1}$ and $C_{2}\left(w_{1}=w_{2}=0.33\right)$, but they are more important than $C_{3}\left(w_{3}=0.20\right)$ which is more important than $C_{4}\left(w_{4}=0.14\right)$. The score matrix is given in Eq. (15). In this case, the problem is not to have no knowledge on some scores but is that they are not cumulative in the same way for each criterion. For $C_{1}$ and $C_{4}$, the score of the disjunction of two alternatives is the sum of individual scores whereas it is not the case for $C_{2}$ and $C_{3}$.

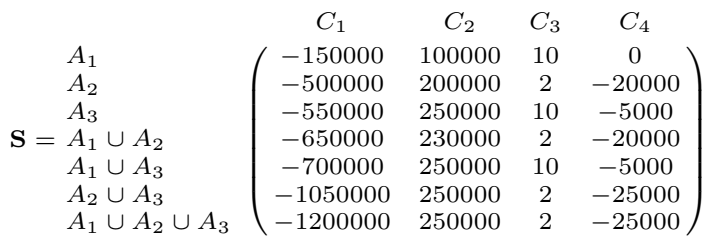


The BBA matrix based on $\mathbf{S}$ using (3), (4), (5), (6), (7) and (8) (rounded to 2 decimal points) is

$$
\left.\begin{array}{lcccc} 
& C_{1} & C_{2} & C_{3} & C_{4} \\
A_{1} & (1,0,0) & (0,1,0) & (1,0,0) & (1,0,0) \\
A_{2} & (0.44,0.10,0.46) & (0.45,0.28,0.27) & (0,1,0) & (0.10,0.67,0.23) \\
A_{3} & (0.37,0.13,0.50) & (1,0,0) & (1,0,0) & (0.70,0.07,0.23) \\
\mathbf{M}=A_{1} \cup A_{2} & (0.27,0.21,0.52) & (0.73,0.10,0.17) & (0,1,0) & (0.10,0.67,0.23) \\
A_{1} \cup A_{3} & (0.23,0.26,0.51) & (1,0,0) & (1,0,0) & (0.70,0.07,0.23) \\
A_{2} \cup A_{3} & (0.04,0.75,0.21) & (1,0,0) & (0,1,0) & (0,1,0) \\
A_{1} \cup A_{2} \cup A_{3} & (0,1,0) & (1,0,0) & (0,1,0) & (0,1,0)
\end{array}\right)
$$

The weighted distances to the ideal best and worst solutions and the relative closeness indicator are listed in Table 3. Based on relative closeness indicator sorted in descending order, the final preference order is $\left(A_{1} \cup A_{3}\right) \succ A_{3} \succ A_{1} \succ$ $\left(A_{1} \cup A_{2}\right) \succ\left(A_{2} \cup A_{3}\right) \succ A_{2} \succ\left(A_{1} \cup A_{2} \cup A_{3}\right)$ : maintaining the existing check dams' series and implementing individual protections is the best option. If the preferences are restricted to single alternatives, one will get as final preference order $A_{3} \succ A_{1} \succ A_{2}$, i.e. option $A_{3}$ (only individual protections) should be preferred by the DM.

Table 3. Average distances and relative closeness indicators.

\begin{tabular}{l|l|l|l|l}
\hline Focal elem. $X_{i}$ & $d^{\text {best }}\left(X_{i}\right)$ & $d^{\text {worst }}\left(X_{i}\right)$ & $C\left(X_{i}, X^{\text {best }}\right)$ & Ranking \\
\hline$A_{1}$ & 0.3012 & 0.6116 & 0.6700 & 3 \\
\hline$A_{2}$ & 0.5668 & 0.3677 & 0.3935 & 6 \\
\hline$A_{3}$ & 0.1830 & 0.7483 & 0.8035 & 2 \\
\hline$A_{1} \cup A_{2}$ & 0.4476 & 0.4901 & 0.5226 & 4 \\
\hline$A_{1} \cup A_{3}$ & 0.1555 & 0.7775 & 0.8333 & 1 \\
\hline$A_{2} \cup A_{3}$ & 0.5562 & 0.3614 & 0.3938 & 5 \\
\hline$A_{1} \cup A_{2} \cup A_{3}$ & 0.8328 & 0.2694 & 0.2444 & 7 \\
\hline
\end{tabular}

\section{Conclusions}

In this paper, we have shown how the BF-TOPSIS approach can be exploited to solve non-classical MCDM problems. This method is relatively easy to use. It does not require the normalization of data and offers a consistent construction of basic belief assignments from the available scoring values. It can also deal with missing scoring values and different criteria weights as well. In this paper only the BF-TOPSIS1 method has been presented, but other more sophisticate BFTOPSIS methods could be also used to solve non-classical problems, but at the price of a higher complexity. The application of this new BF-TOPSIS approach to solve non-classical MCDM problems for natural risk prevention is currently under evaluation, and it will be reported in a forthcoming publication. 


\section{References}

1. Saaty, T.: The Analytic Hierarchy Process. McGraw-Hill, New York (1980)

2. Dezert, J., Tacnet, J.-M., Batton-Hubert, M., Smarandache, F.: Multi-criteria decision making based on DSmT/AHP. In: Proceedings of the International Workshop on Belief Functions, Brest, France (2010)

3. Dezert, J., Tacnet, J.-M.: Evidential reasoning for multi-criteria analysis based on DSmT-AHP. In: Proceedings of the ISAHP 2011, Italy (2011)

4. Tacnet, J.-M., Dezert, J., Batton-Hubert, M.: AHP and uncertainty theories for decision making using the ER-MCDA methodology. In: Proceedings of the ISAHP 2011, Italy (2011)

5. Ennaceur, A., Elouedi, Z., Lefevre, E.: Multi-criteria decision making method with belief preference relations. Int. J. Uncertainty Fuzziness Knowl. Based Syst. (IJUFKS) 22(4), 573-590 (2014)

6. Ennaceur, A., Elouedi, Z., Lefevre, E.: Belief AHP method: AHP method with the belief function framework. Int. J. Inf. Technol. Decis. Making (IJITDM) 15(3), 553-573 (2016)

7. Wang, X., Triantaphyllou, E.: Ranking irregularities when evaluating alternatives by using some ELECTRE methods. Omega 36(1), 45-63 (2008)

8. Hwang, C.L., Yoon, K.: Multiple Attribute Decision Making. Lecture Notes in Economics and Mathematical Systems, vol. 186. Springer-Verlag, Berlin (1981)

9. Lai, Y.J., Liu, T.Y., Hwang, C.L.: TOPSIS for MODM. Eur. J. Oper. Res. 76(3), 486-500 (1994)

10. Dezert, J., Tacnet, J.-M.: Soft ELECTRE TRI outranking method based on belief functions. In: Proceedings of the 15th Fusion Conference, Singapore (2012)

11. Dezert, J., Han, D., Yin, H.: A new belief function based approach for multicriteria decision-making support. In: Proceedings of the 19th International Fusion Conference, Heidelberg, Germany (2016)

12. Carladous, S., Tacnet, J.-M., Dezert, J., Han, D., Batton-Hubert, M.: Evaluation of efficiency of torrential protective structures with new BF-TOPSIS methods. In: Proceedings of the 19th Fusion Conference, Heidelberg, Germany (2016)

13. Shafer, G.: A Mathematical Theory of Evidence. Princeton University Press, Princeton (1976)

14. Han, D., Dezert, J., Yang, Y.: New distance measures of evidence based on belief intervals. In: Proceedings of the 3rd Belief International Conference, Oxford (2014)

15. Dezert, J., Han, D., Tacnet, J.-M., Carladous, S., Yang, Y.: Decision-making with belief interval distance. In: Proceedings of the 4th Belief International Conference, Prague, Czech Republic (2016)

16. Irpino, A., Verde, R.: Dynamic clustering of interval data using a wasserstein-based distance. Pattern Recogn. Lett. 29, 1648-1658 (2008) 